\title{
Graphic visualisation of hybrid learning contexts
}

\author{
Andrea Manciaracina ${ }^{a}$ \\ aPolitecnico di Milano, Department of Design \\ *andrea.manciaracina@polimi.it
}

\begin{abstract}
:
The arrival of the pandemic has accelerated the need to transform learning environments and the way education is delivered. Universities have been faced with sudden changes. Teachers have been called upon to adapt their technological skills and redesign their courses to meet the new needs for interaction in new digital learning environments. With the possible return to normality, lecturers will need tools to help them re-contextualise their teaching activities and choose and relate appropriate technologies within physical (on-site) and digital (online) learning environments. Therefore, their task will be to design hybrid learning contexts. This paper discusses the results of performative experimentations carried out with teachers from the School of Design of the Politecnico di Milano to test the capabilities of an instructional design tool in creating graphic spatial visualisations of hybrid learning contexts.
\end{abstract}

Keywords: hybrid learning; instructional design; graphic spatial concepts

\section{Towards a convergence of digital and physical}

With the arrival of Covid19 at the start of 2020, higher education institutions had to respond quickly to guarantee the smooth running of all the didactic activities (UNESCO, 2020). Universities have been compelled to make significant changes (Barbati, 2020; EUA, 2020; OECD, 2020) due to the widespread adoption of digital technologies. As a result, today's classroom has extended past four walls into what is known as "virtual space", allowing learning to happen virtually anywhere and anytime (Trentin, 2015). Then, it is possible to think of the evolution of teaching environments in which analogical and digital, physical, and intangible aspects will contribute to creating the right conditions for teachers to improve the relationships between the different actors involved in the learning process.

In this paper, the term hybrid learning refers to learning that co-occurs in a physical space (on-site) and a virtual space (online). The fundamental purpose of technological tools, particularly those connected to the web, is to open up new educational possibilities found in these hybrid environments (Tovmassian, 2004) in which various degrees of technology are present, rebounding from physical to digital spaces and in which "space is not a thing but a process" (Boys, 2009). 


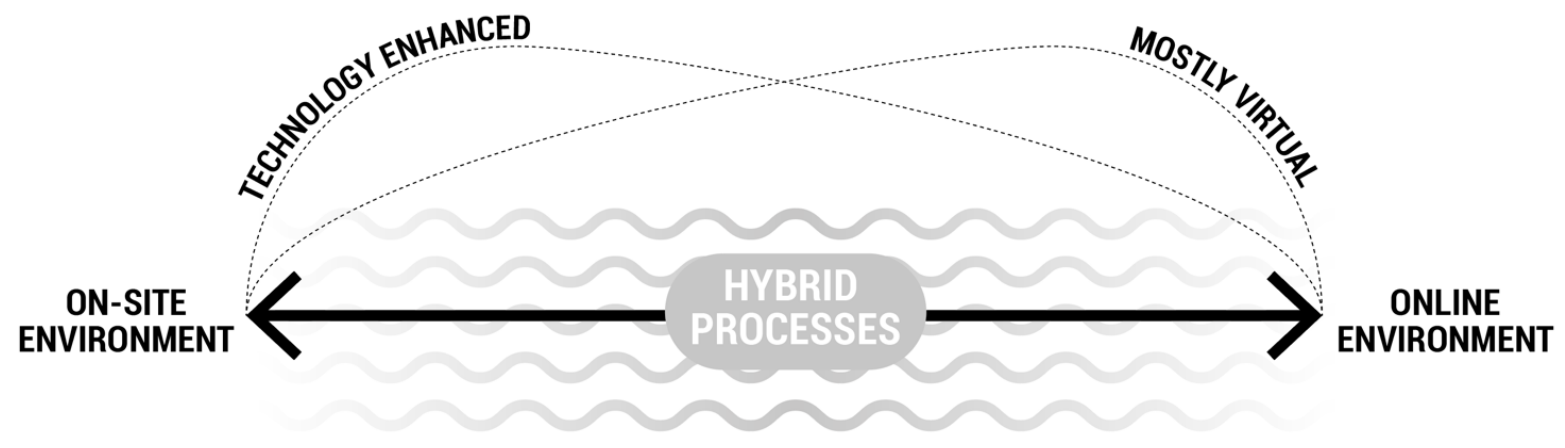

Figure 1. The spectrum of the hybrid learning process (edited from Graham et al., 2013)

The recent health crisis has created new troubles and opportunities for instructors in terms of developing new instructional paths and broadening the scope of learning.

To react to this challenge and to facilitate future actions, I created a graphic and instructional design tool (within a doctoral research carried out at the Politecnico di Milano) capable of delivering a variety of distinct yet consistent and cohesive graphic design solutions. Throughout the design process, the tool incorporates diverse "non-designers" in various co-design activities (Sanders et al., 2010), allowing them to feel the pride to take ownership of the process, resulting in a long-term sustainable implementation (Sanders et al., 2010).

The aim of the co-design activities was to test the tool and its ability to activate reflection and awareness in the use of learning technologies and the design of hybrid learning contexts.

\section{Designing new hybrid learning contexts}

Cameron (2009) defines learning design as the "aims of providing teachers with a framework capable of bridging the gap between rich, descriptive models and technologies, and the everyday practice and understanding of teachers". Furthermore, Koper (2005) defines learning design "as the application of learning design knowledge when developing a concrete unit of learning, where the quality of a unit of learning depends largely on the quality of the learning design". The learning design backed by appropriate instructions and specifications can help teachers reconsider usual teaching methods and adopt new pedagogical approaches (Beetham, 2007). Moreover, a learning design toolkit can embrace technological tools to support the planning, the design and the delivery of learning (Beetham, 2007) and learning spaces.

The provision of appropriate tools to reflect on the use of digital technology in daily practice emerges as necessary to shape hybrid learning contexts. Furthermore, providing a tool means to support teachers' instructional design that becomes essential to address issues and possibilities afforded by technology. The tool cited in this paper aims to assist the teachers in reflecting on creating new hybrid learning contexts, including all the tools, documents, and other devices, that coexist to create a learning environment (Goodyear, 2001). It is a graphic tool that can give origin to various spatial hybrid concepts through a user-centred approach. It allows reflecting on different dimensions at the same time: the temporal dimension of the educational flow (step 1); the dimension of the user's needs (step 2); the educational dimension of the teaching clusters (step 3); the technological dimension of the 12 selected tools (step 4). The teacher realises, through step 5, a graphic visualisation of the space, the subject of this paper, inserting users and technologies to develop 
relationships and opportunities visually and reflecting on the spatial dimension of interactions between users, technologies, and on-site/online environments.

STEP 1 ACTIVITIES TIMELINE

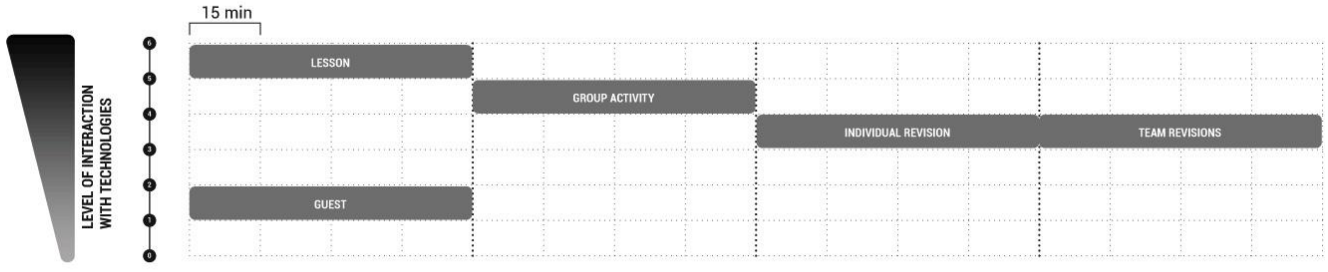

STEP 2 USERS' NEEDS

CLASS OF 50 STUDENTS
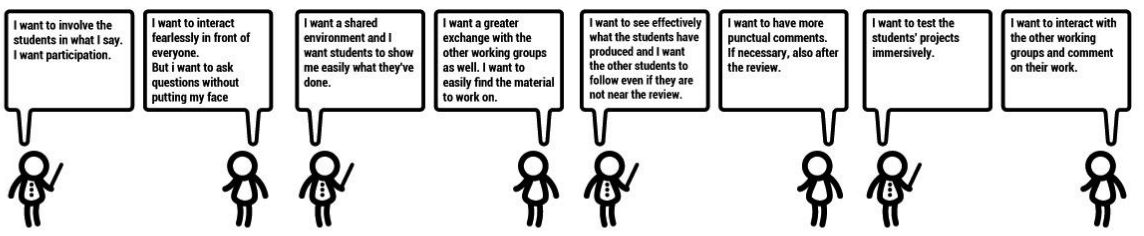

STEP 3

DIDACTIC CLUSTERS

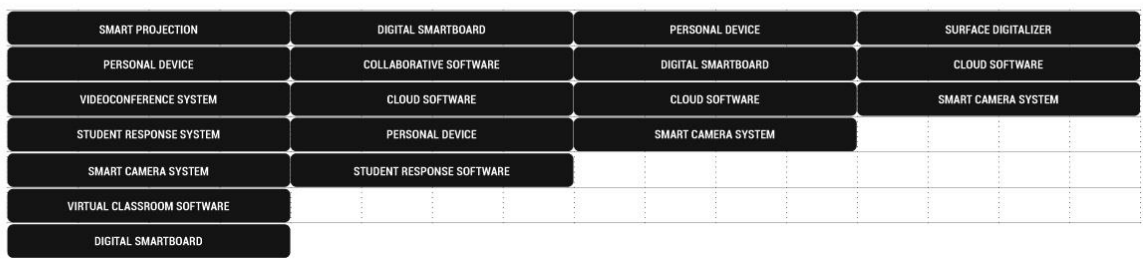

Figure 2. Examples of steps 1-4

The selection of the technologies present in the tool (listed in Table 1) is the outcome of all reviews, observations, experiences, and design actions conducted during the doctoral research activities. The technologies chosen were those commonly utilised in a variety of situations, learning environments, and experiments.

Table 1. Research actions and selected technologies

\begin{tabular}{|c|c|c|c|c|c|}
\hline TECHNOLOGIES & $\begin{array}{l}\text { LITERATURE } \\
\text { CASE STUDY }\end{array}$ & $\begin{array}{l}\text { VISITED CASE } \\
\text { STUDY }\end{array}$ & $\begin{array}{c}\text { ONLINE } \\
\text { ENVIRONMENT } \\
\text { SURVEY } \\
\end{array}$ & $\begin{array}{c}\text { ON-SITE } \\
\text { ENVIRONMENT } \\
\text { SURVEY } \\
\end{array}$ & FIELD RESEARCH \\
\hline $\begin{array}{l}\text { Digital } \\
\text { Smartboard }\end{array}$ & & & & & \\
\hline $\begin{array}{l}\text { Analogic } \\
\text { Smartboard }\end{array}$ & & & & & \\
\hline Smart Projection & & & & & \\
\hline $\begin{array}{l}\text { Videoconference } \\
\text { System }\end{array}$ & & & & & \\
\hline
\end{tabular}




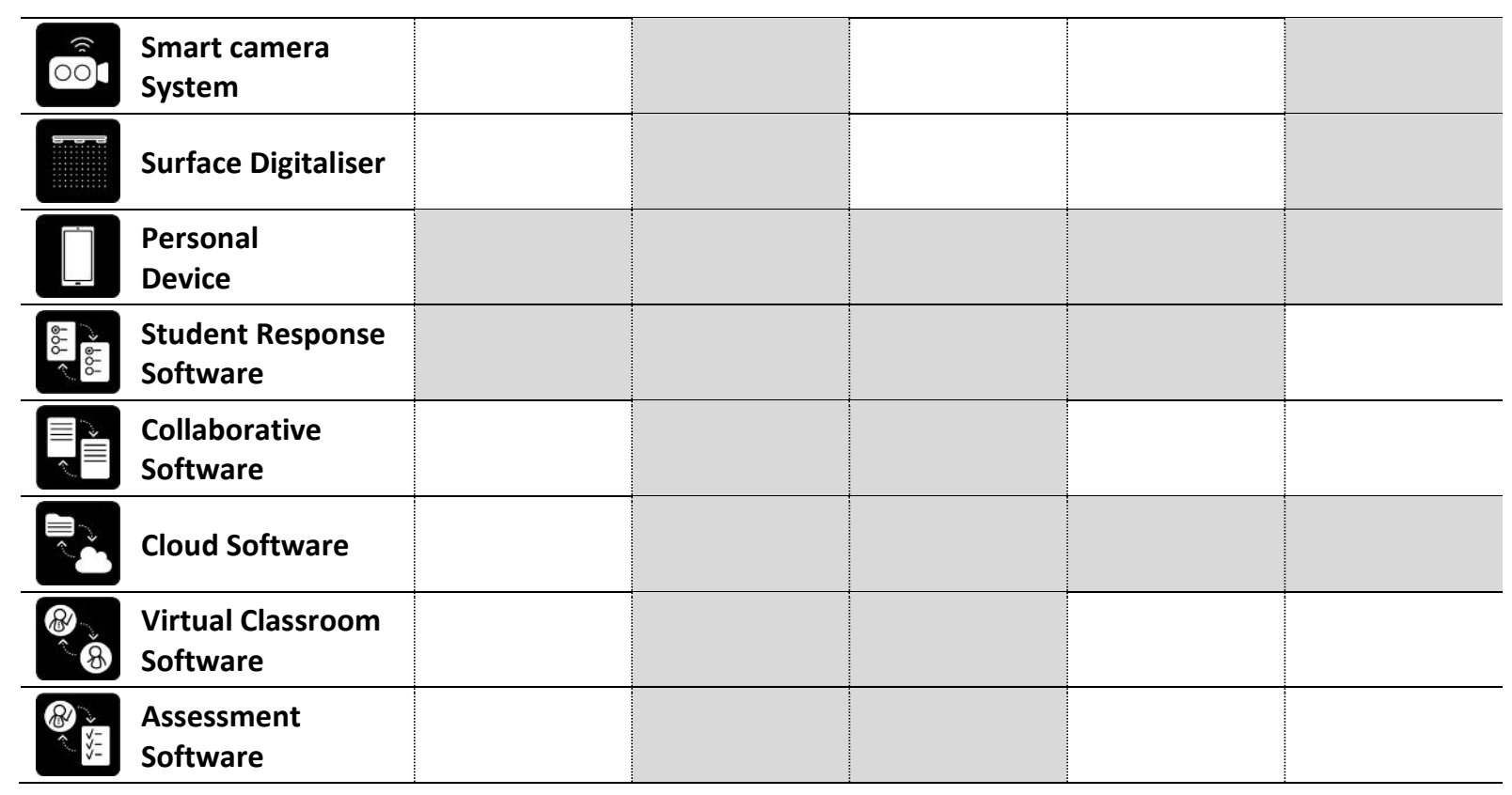

Teachers have at their disposal two graphic elements representing two learning environments (onsite and online). They must insert the symbolic elements of the technologies (technology icons), the users (teacher's and student's icons) and projection's points (projections' icon) in the two spaces. Finally, the teachers must create links between the two environments to correctly indicate the technologies involved in the implementation of relationships between the physical and digital world.
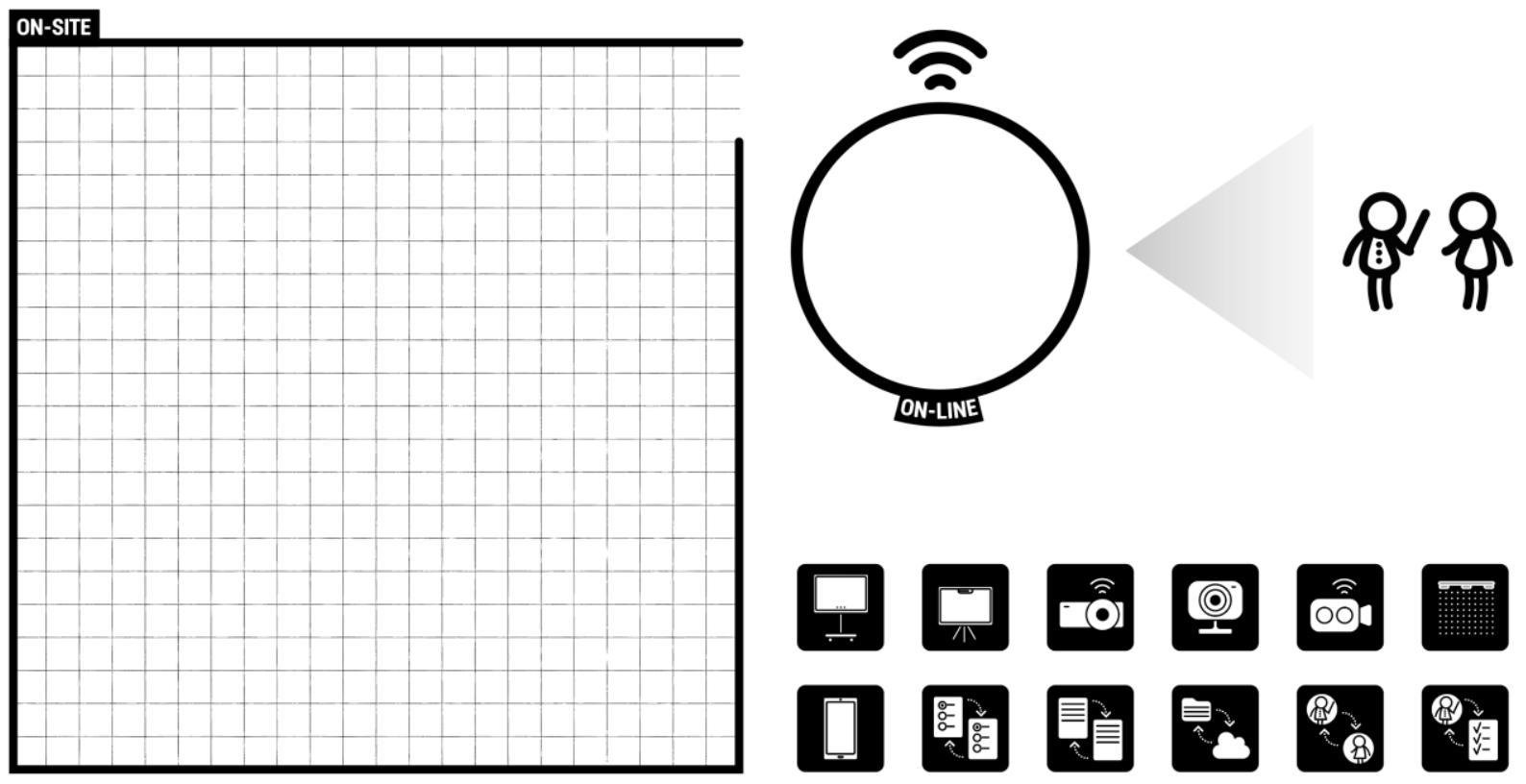

Figure 3. Spatial graphic elements of step 5

\section{The point of view of design disciplines}

\subsection{Performative experimentation}

The tool was tested, in September 2020, through 8 performative co-design activities, with teachers from the School of Design of Politecnico di Milano. The group selected corresponds to a profile of 
professors between the ages of 30 and 45 , young enough to have a future-oriented teaching perspective yet with sufficient experience to construct and design their teaching activity. They have been selected to have both disciplinary and courses' variety with the presence of: manual activities to verify the correct application of the taught method; activities related to design processes teaching; large number of students (over 100); physical experience of objects and materials; a mix of design and engineer disciplines; web technologies as the central theme.

Table 2. Teachers involved

\begin{tabular}{lllll}
\hline TEACHER & COURSE TYPE & DEGREE COURSE & COURSE TITLE & COURSE SUBJECT \\
\hline T1 & Design & Product Design & Drawing studio & Technical \\
\hline T2 & Design & Product Design & Meta-design studio & Technical \\
\hline T3 & Theoretical & $\begin{array}{l}\text { Communication } \\
\text { Design }\end{array}$ & $\begin{array}{l}\text { Innovation culture } \\
\text { and theories }\end{array}$ & Humanistic \\
\hline T4 & Theoretical & Fashion Design & History of fashion & Humanistic \\
\hline T5 & Elective & All courses & Materials and nanotechnology & Scientific \\
\hline T6 & Design & Design & Product development design & Technical \\
\hline T7 & Design & Interior Design & Meta-design studio & Technical \\
\hline T8 & Elective & All courses & Software and graphic for the web & Technical \\
\hline
\end{tabular}

The collaborative environment chosen was Miro, a web-based platform composed of graphic elements, including a digital whiteboard.

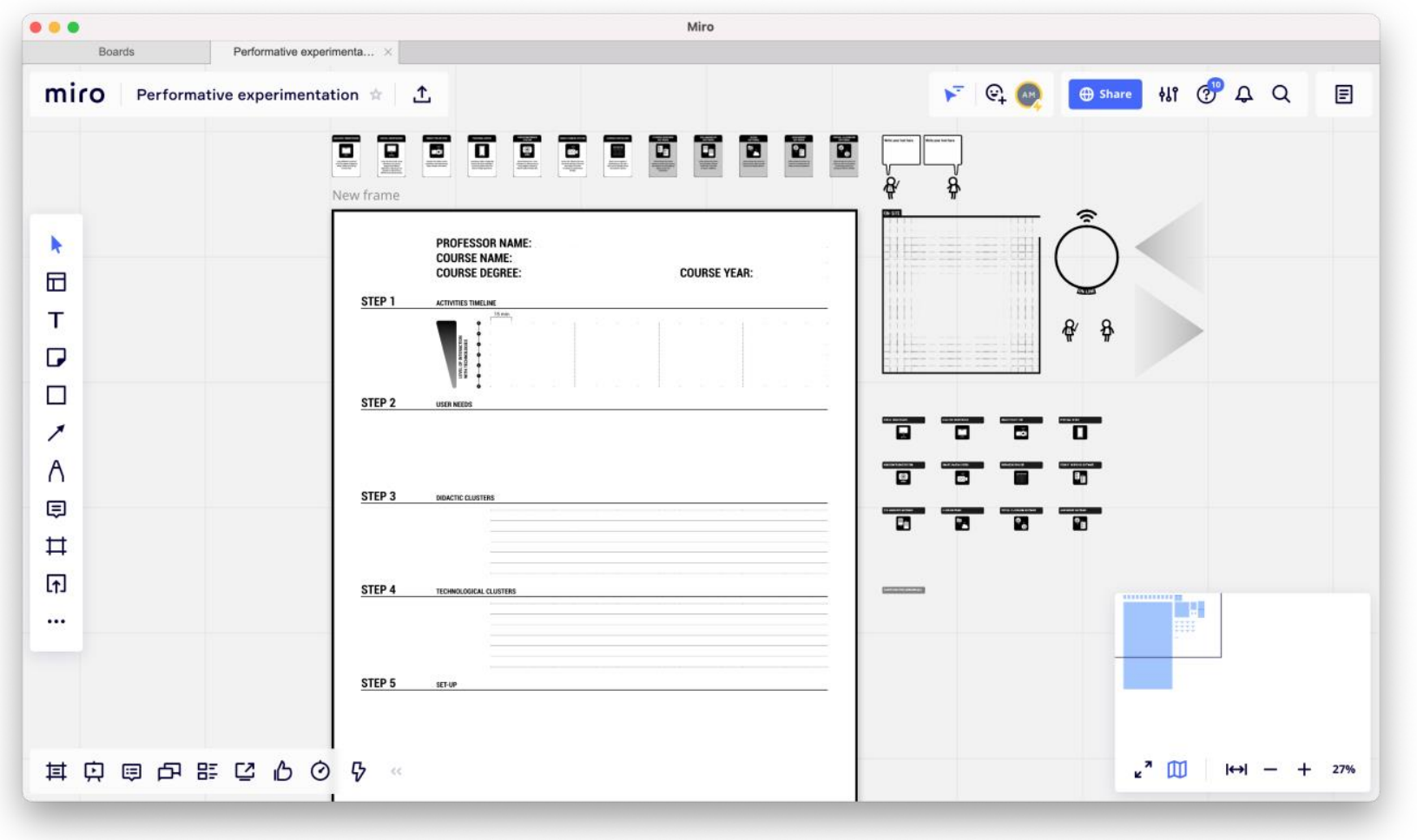


At the end of the activity, they were asked for a subjective judgment on the quality of the tool and about its effectiveness as an instrument for reflecting on the design of spatial graphic concepts of hybrid learning contexts.

In this paper, the spatial concepts realised by the teachers (corresponding to step 5 of the tool) in the co-design activity will be illustrated below. The spatial concepts are the graphic synthesis of the decisions taken by the teachers in the previous steps (from 1 to 4 ) in which the reflections on learning units, users' needs, and technologies were activated.

\subsection{T1's spatial concept}

T1 offers a course (Drawing Studio) that includes numerous manual activities that the teacher must supervise. T1 takes an active role in the process, intervening directly on the students' outcomes to indicate the pieces that need to be corrected. $\mathrm{T} 1$ conveys and shares knowledge about a method, as well as accepting feedback, confirming, and validating the achievement of a learning objective. The technologies denoted by $\mathrm{T} 1$ are strongly associated with active learning, manual execution of activities, and sharing of findings. As a result, we find technologies that provide rapid feedback on students' comprehension, collaborative technologies for sharing and manipulating works, and immersive technologies for virtualization with pin-up sessions of works. T1 visualises two spatial propositions. In the first, the space is outfitted with two projections and technologies that enable remote interventions by students and guests. In the second, the space is provided for the staging of students' work and a collaborative discussion of the activities' outcomes. Students and teachers are equipped with personal technology that enables them to edit and exchange results in both spatial configurations digitally. T1 deemed the tool handy and agreed on the fundamental principle of encouraging extensive use of technology.
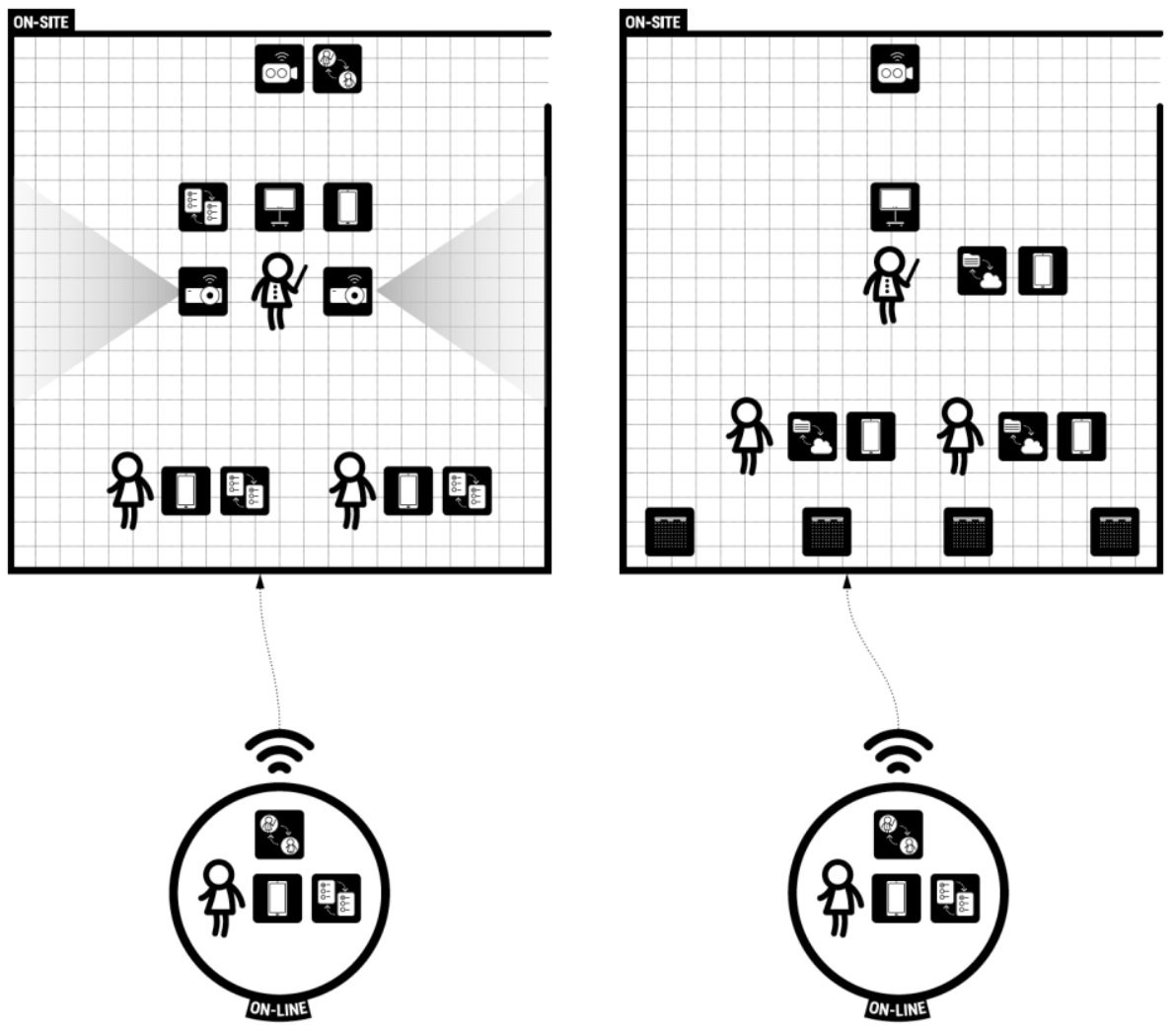

Figure 5. T1's output 


\subsection{T2's spatial concept}

T2 teaches the Meta-design studio, a course devoted to the teaching of design processes. The technologies denoted by $\mathrm{T} 2$ are numerous and cross-cutting, reflecting the course's and teachers' technical approach. As a result, we find technologies that enable the creation of collaborative environments with file and information sharing, technologies that enable remote guest connection and interaction with students, and technologies that enable the execution of research activities and their sharing and discussion. T2 offers two spatial configurations, both of which include a projection point. In the first, the space is filled with technology that enables teachers and external visitors to deliver lectures and the ability for students to interact effectively with the speaker. In the second, collaborative learning activities and digital design output generating activities are made possible. Students and professors in both spatial configurations are supplied with personal technology that enables them to communicate with one another and create material and information. $T 2$ found the tool beneficial for compiling his own "wish list" of technologies that could be incorporated into hybrid learning activities and processes.
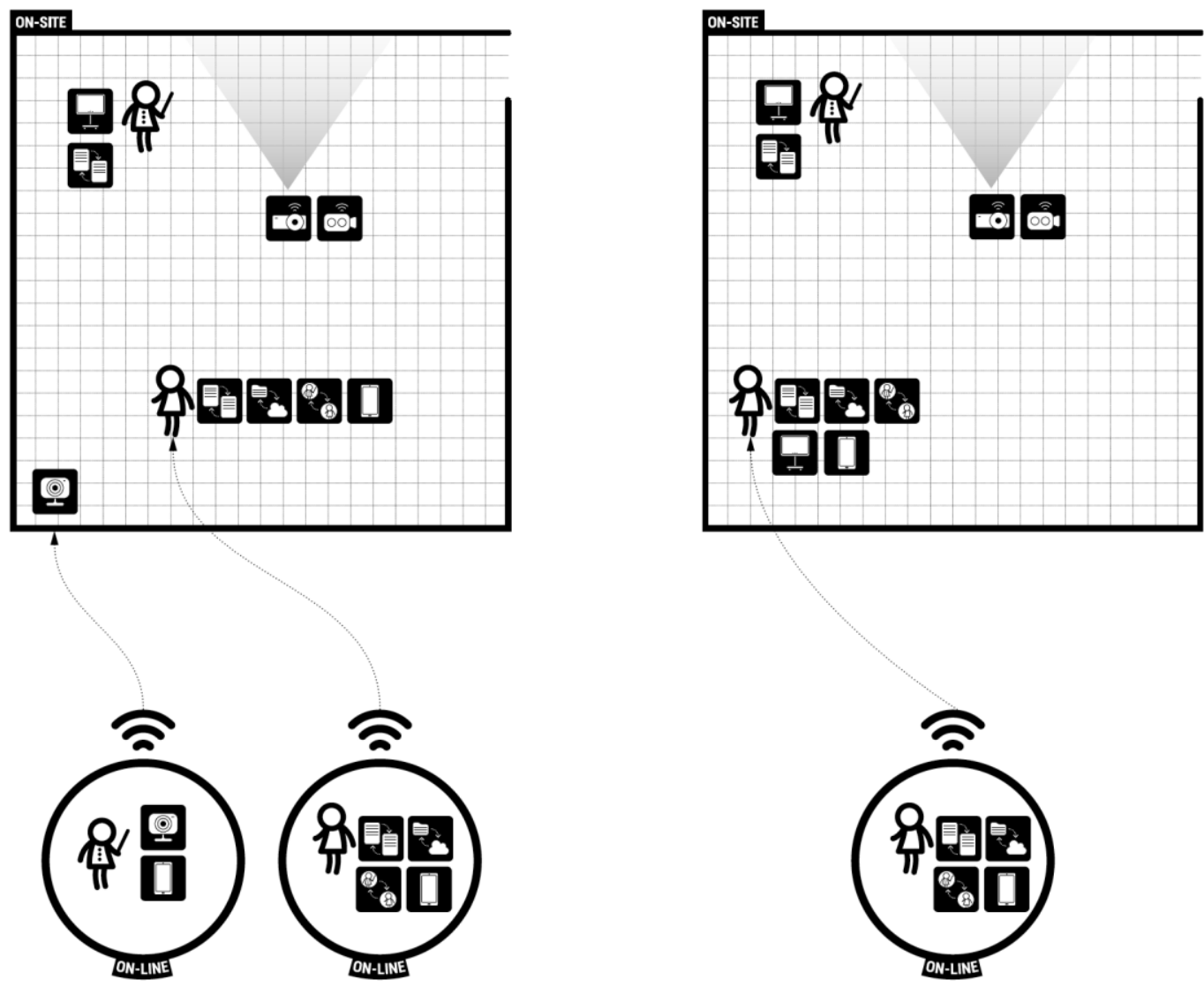

Figure 6. T2's output

\subsection{T3's spatial concept}

T3 focuses on sociological subjects and delivers an approximately 100-student theoretical course. T3 assigns reading tasks to his students before the classroom session and then implements flipped classroom activities. Such a large number of students frequently precludes a complete presentation of all topics. T3's technologies are inextricably linked to active learning, peer discussion, and collaborative activities. As a result, we observe technologies that enable students to communicate with one another by asking them content-related questions and providing prompt feedback, collaborative technologies for cluster building, and mind maps (leaving a digital and reusable trace of 
what has been generated). T3 suggests two alternative spatial arrangements. In the first, the space features two projection points, technology that enable blended activity, student and distant guest interventions, and an active approach with remote users. In the second, the space is devoted to the collaborative part of the activities, allowing for peer conversation via virtual platforms. Users in both spatial configurations are provided with personal technology to participate in discussions and contribute material and information. T3 judged the tool extremely beneficial for activating a previously inactivated mental reflection area, which would not have occurred independently.
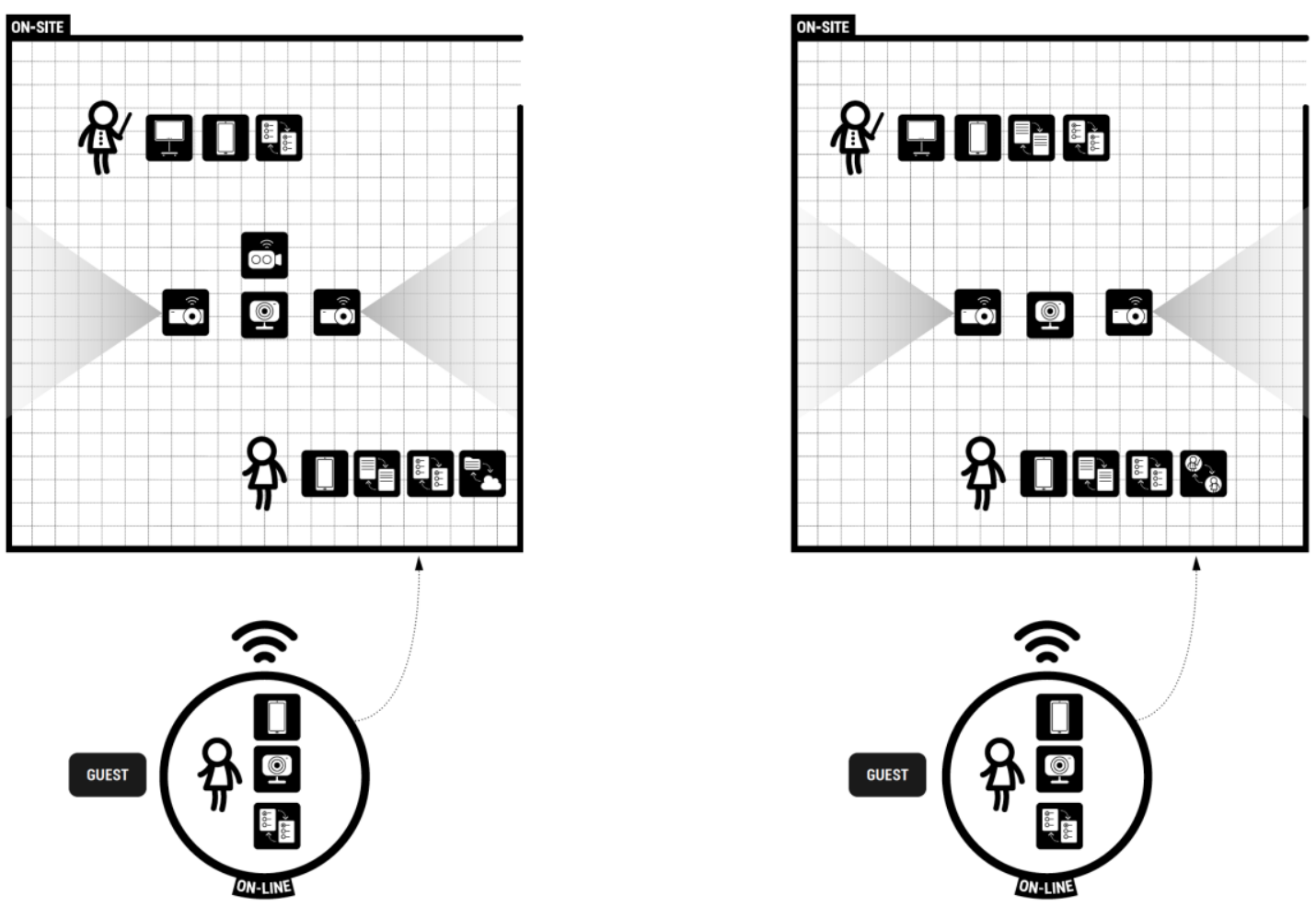

Figure 7. T3's output

\subsection{T4's spatial concept}

T4 teaches around 180 students in a challenging course on project management or collaborative activities. T4 wishes to replicate the dynamics of a digital realm in a physical space. T4 adopts a constructivist approach, requiring students to be active participants in the lesson's and content's construction. The technologies are used to show and construct information, administer questionand-answer sessions, and develop collaborative research activities. The large number of students complicates traditional interaction management; T4 looks for technologies that enable students to participate in courses via virtual space quite appealing. T4 suggests two alternative spatial arrangements. In the first, the space is equipped with two projection points and technology that enables interaction between the teacher, and the displayed information and student feedback. In the second, the space is shaped for discussion and collaborative activities, thereby assisting pupils more constructively. Students and teachers are equipped with personal technologies to revise and share information and research activities in both space configurations. T4 rated the co-design activity as highly favourable due to the stimulation provided by comparison and discussion.

T4 considered how technology could assist him in a large classroom. 

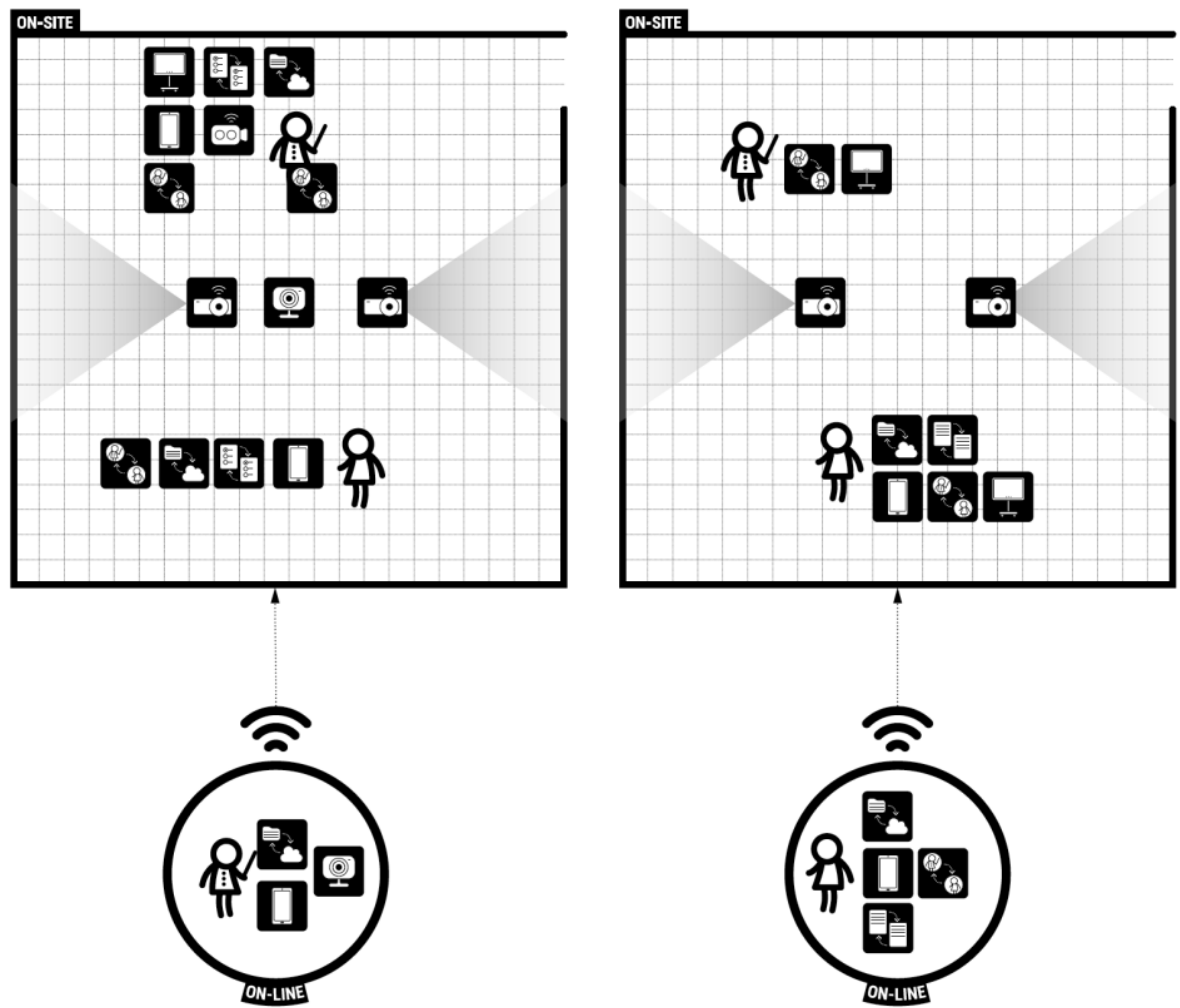

Figure 8. T4's output

\subsection{T5's spatial concept}

T5's course contains numerous exercises involving visualising and analysing materials samples, which require the teacher's supervision to ensure their comprehension and categorisation. T5 takes an active role in the content offered and enlists the assistance of external experts to focus on specific types of materials. The technologies denoted by T5 are inextricably linked to active learning and the co-creation of the lesson with the students. As a result, we notice technologies that enable the verification of students' comprehension through appropriate quick assessment activities, collaborative technologies for sharing information necessary for subsequent actions, collaborative technologies for creating knowledge (diffused smartboards), and remote management technologies for students and external guests. T5 suggests two alternative spatial arrangements. The first is a space outfitted with four projection points to maximise visual information transfer. Additionally, there are technologies that enable students and guests to intervene remotely, as well as tools for managing active learning. In the second, the space is provided for collaborative elaboration and discussion of the activities' outcomes. Students and professors in both space configurations are supplied with personal devices to generate and exchange knowledge, in addition to the shared technology in the physical space. T5 recognized the tool's utility in building additional courses after utilizing it. T5 was not anticipating such a highly structured output as the one delivered. 

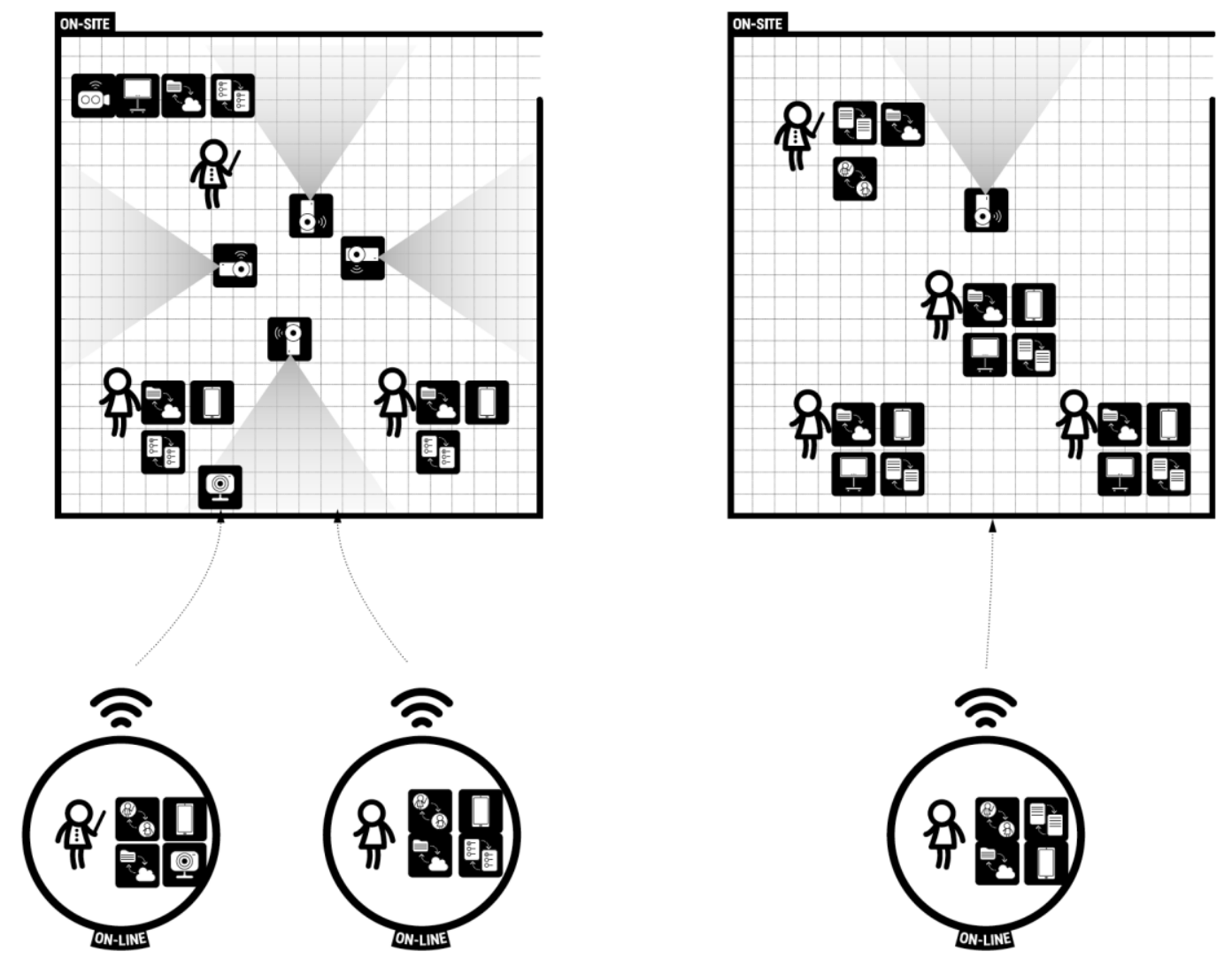

Figure 9. T5's spatial graphic concept

\subsection{T6's spatial concept}

T6 provides a course with many engineering components that is taught by both mechanical and materials engineering faculty. T6 displays a desire for immediate feedback on students' attention and wishes for the same level of natural engagement with online and on-site students. T6 technologies are inextricably linked to an active and collaborative learning strategy, which necessitates visual references and visual supports for engagement and discussion with users in the classroom and at a distance. As a result, we identify technologies that enable user interaction with software for virtual classrooms, verification of students' comprehension with a rapid feedback, collaborative technologies for sharing and manipulating information, and immersive wall technologies for displaying the results of exercises with evaluations and peer discussion. T6 suggests three different spatial layouts. In the first, the space is outfitted with two projection points and technologies that enable students to engage in remote interventions. In the second, the space allows for collaborative work and design outcomes' revision. In the third, the space provides for the staging of students' work and collective discussion of the activities' outcomes. Students and teachers are empowered with personal technologies in all spatial configurations to intervene in lessons, interact, and share information. Finally, T6 gave the tool a positive evaluation. 


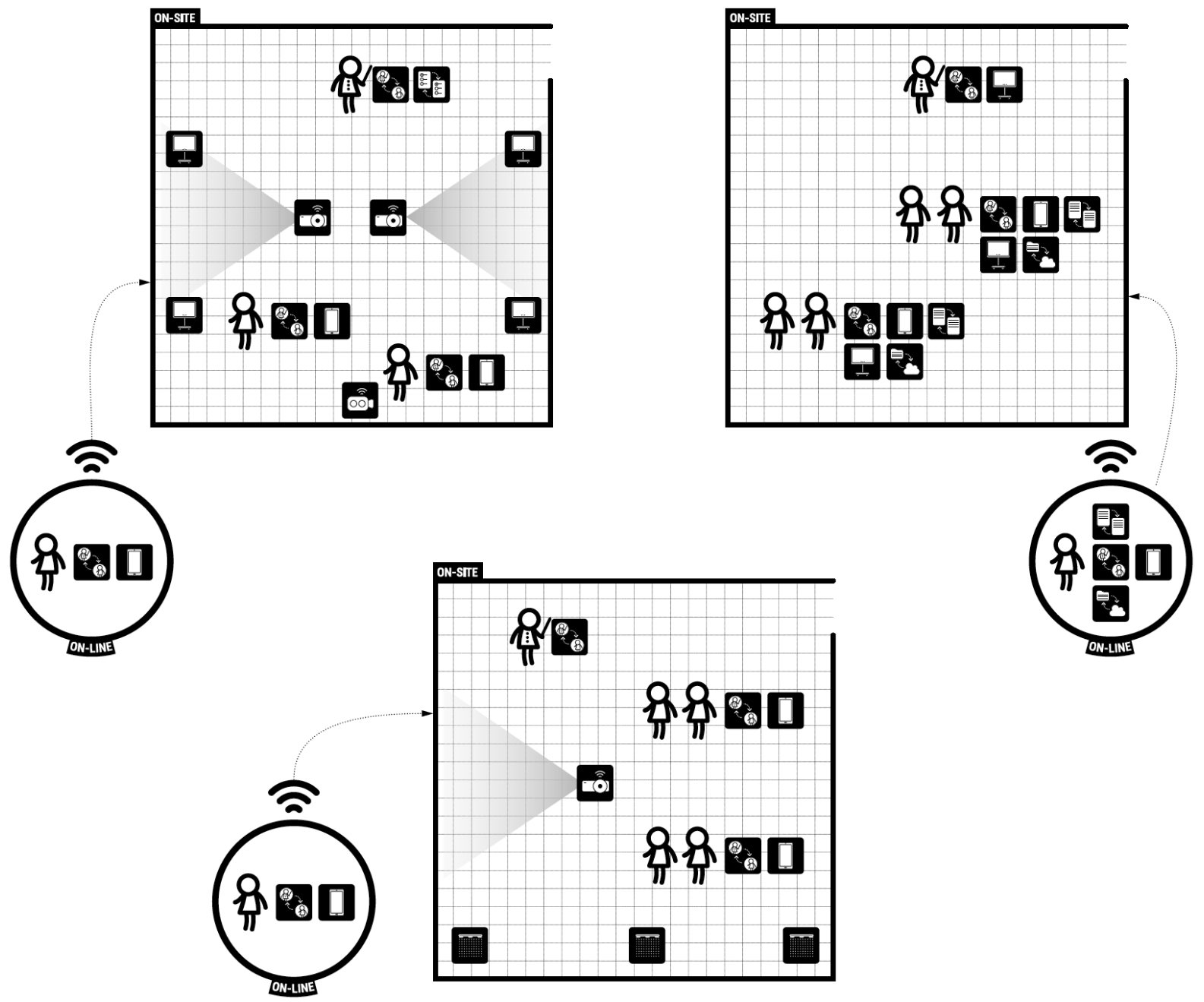

Figure 10. T6's output

\subsection{T7's spatial concept}

T7 teaches the Interior Design Degree's Meta-design studio. Students participate in both solo and group tasks in this course, and T7 intervenes directly on students' outcomes to suggest the aspects that must be improved. T7 communicates and collaborates on all the elements of the course and aspires to create an immersive environment in which students' final projects can be evaluated. T7's chosen technologies are inextricably linked to an active learning approach, to collaborative content creation, and to shared interaction. T7 suggests four spatial configurations. In the first, the space is outfitted with two projection points and technology that enable students to participate, to take an active role, and to interact with remote guests. In the second, the space enables the development of collaborative projects that utilise shared technologies. In the third, the space accommodates devices that facilitate engagement with teachers. In the fourth, teachers and students collaborate to test the projects using immersive technologies. Students and teachers are provided with personal devices that enable them to interact with content and one another in various space arrangements. T7 found the tool quite beneficial in reflecting on the redesign of instructional activities in a hybrid context. 

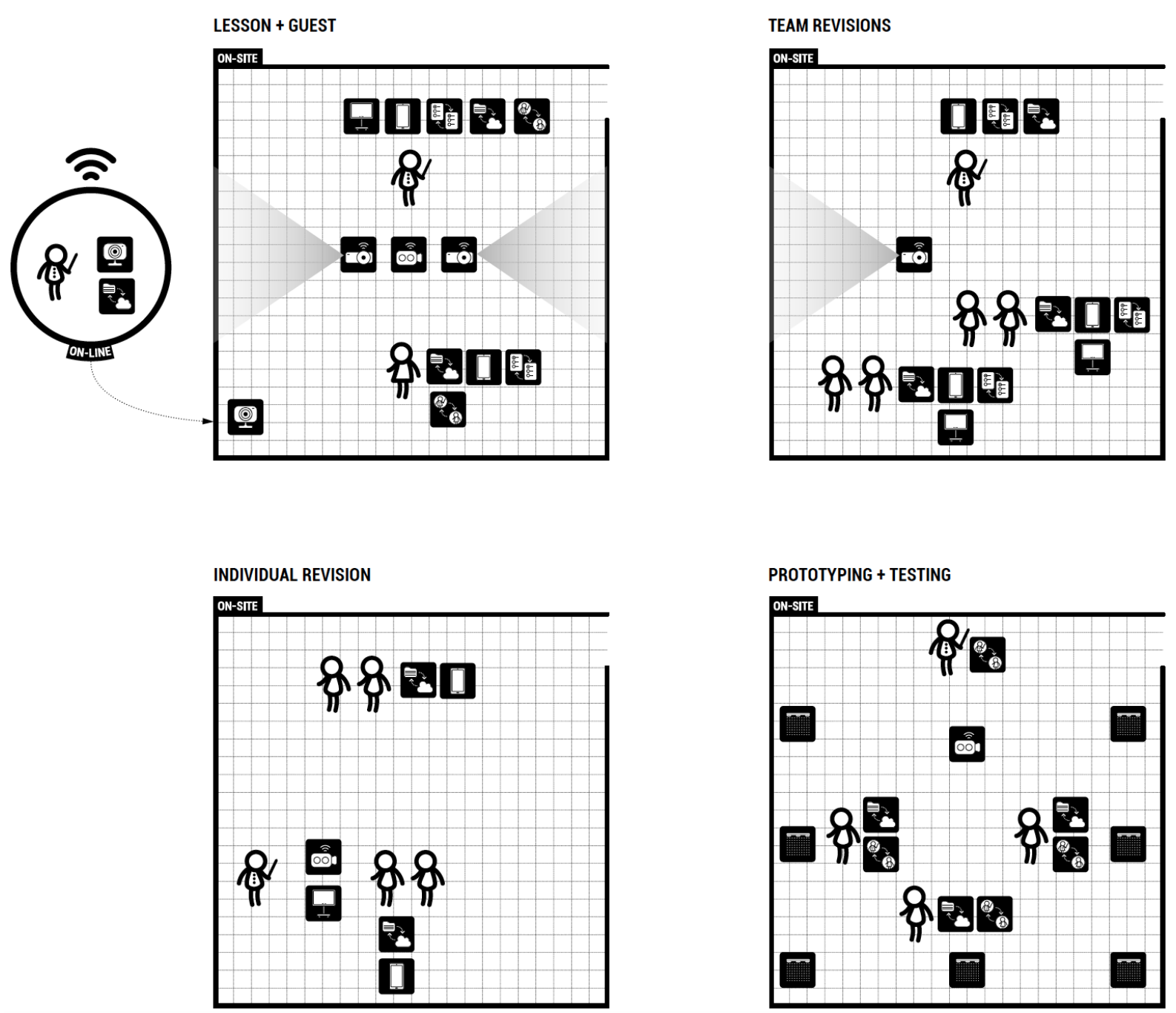

Figure 11. T7's output

\subsection{T8's spatial concept}

T8, who already possesses a high level of technological proficiency, teaches a course focused on web technologies. T8 takes an active role in the material and information offered, sparkling dialogue, and refining the design path several times to ensure its correctness. T8 has chosen to test the final day of the course, which is dedicated to the final presentations of the projects. In this case, a portion of the lesson can be conducted remotely (presentation and discussion session) and another portion inperson (brief reviews of individual projects). T8's technologies are closely related to online and onsite course management, to the delivery of active learning activities, and to the sharing of outcomes. As a result, we observe tools that enable rapid feedback on students' comprehension and collaborative platforms for sharing and manipulating information. T8 offers three distinct spatial arrangements. The first (lesson), in which the space is equipped with a projection point and technologies that enable students to intervene both in the classroom and remotely. In the second (presentation), the space is provided for the staging of students' work and the collaborative discussion of the activities' outcomes. In the thirds (review), the space facilitates contact between individual students and teachers. Students and teachers are empowered with personal devices to conduct feedback and peer review activities in all spatial configurations. T8 judged the tool as beneficial from the perspective of a technology expert for those inexperienced users that are about to build their courses in a new hybrid context. 

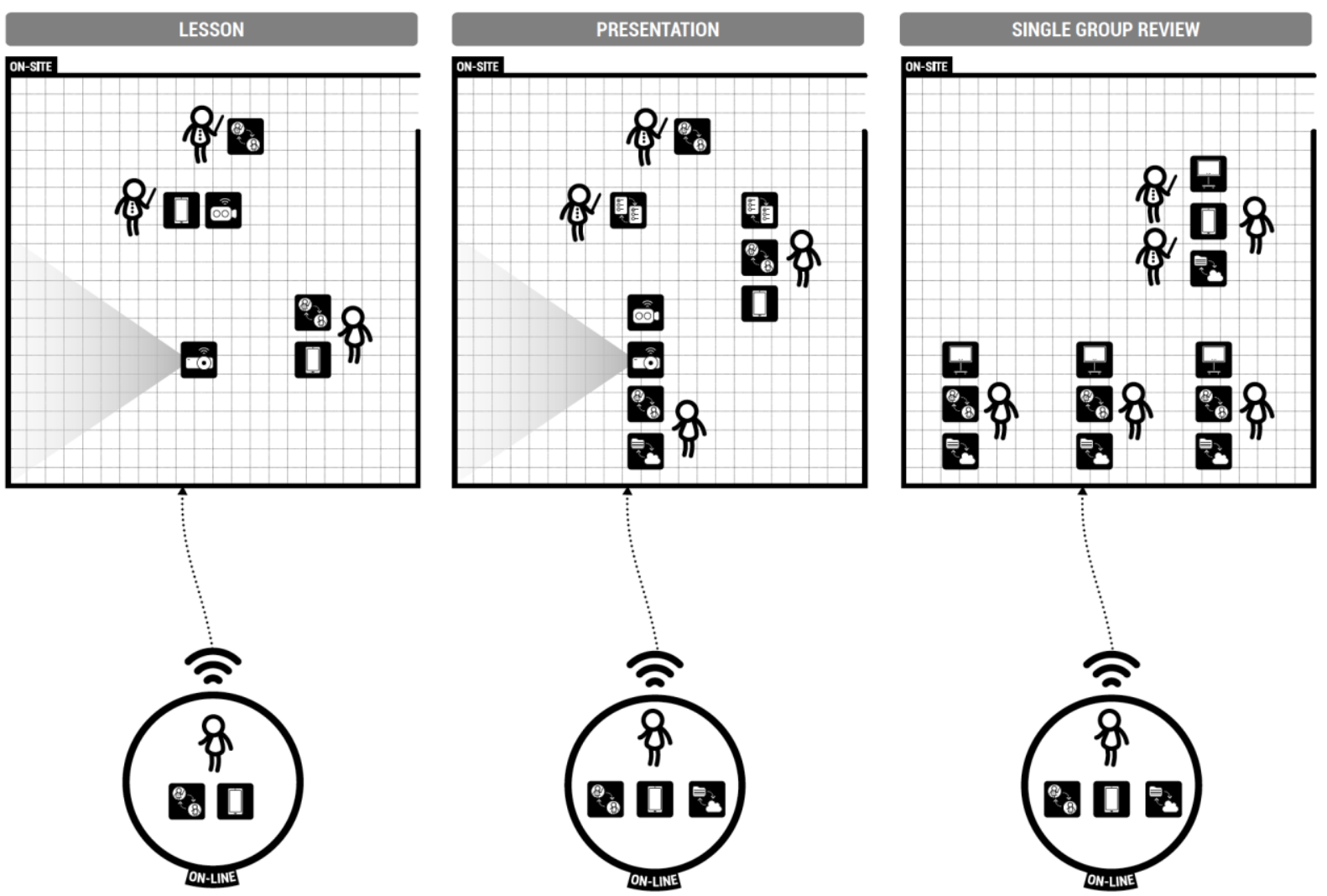

Figure 12. T8's spatial graphic concept

\section{Conclusions and future outcomes}

All the teachers involved in the performative experimentations stated that the tool proved to be very useful in addressing the technological aspects of a teaching redesign in hybrid learning contexts. The ability of the tool to facilitate reflection and the creation of relationships between pedagogy, space, technology (Radcliffe et al., 2008), and users were also confirmed. The teachers appreciated the tool's graphic characteristics and simplicity. Through the graphic visualisation of the space, the teachers were able to check whether the quantity of a given technology was sufficient or determine new relationships between physical or virtual learning environments, or even define the need for new relationships and, therefore, new technologies. Thanks to its visual characteristics, the tool allowed the teachers to set new and unexpected reflections in motion and to focus on users' interactions with technologies.

Regarding the hybrid learning processes, the performative experimentation brought to light many interesting reflections:

- the transfer of some pieces of discussion asynchronously through the software for virtual classes;

- the management of parts of an on-site course in online environments, especially in courses with a large number of students;

- the transformation of some parts of the physical space into immersive environments for simulation and testing of design concepts;

- the transformation onto the virtual presence of all the interventions of distant students and/or international guests;

- the multiplication of display points in the physical space through multiple projections and personal devices. 
It must be underlined that the tool does not address all matters related to the spatial design of a hybrid learning environment. Physical pace is treated within the design tool as part of the graphic output, but its exploration does not go beyond that. A limitation of the experiment lies in the sample chosen for testing (the tool) which was not conducted with the involvement of decision-makers and facilities managers.

At the time of writing this paper, the tool is being redesigned to function as a web platform, to make the creation of outputs simple and straightforward, and to create a database of data to aid decisionmaking in the technological implementation of teaching spaces and activities. Further steps of the ongoing research are thus foreseen.

\section{References}

Barbati, C. (2020). Le università "alla prova" della transizione digitale. Editoriale Scientifica.

Beetham, H. (2007). An approach to learning activity design. In H. Beetham \& R. Sharpe (Eds.), Pedagogy for a Digital Age. Designing and delivering e-learning. Routledge. http://digilib.unila.ac.id/4949/15/BAB II.pdf

Boys, J. (2009). Beyond the Beanbag? Towards new ways of thinking about learning spaces. Networks Magazine, 08, 16-19. http://arts.brighton.ac.uk/_data/assets/pdf_file/0019/64180/Jos-Boys-articleNetworks08-pages-16-19.pdf

Cameron, L. (2009). How learning design can illuminate teaching practice. The Future of Learning Design Conference., [Online]. http://ro.uow.edu.au/fld/09/Program/3/ [Date Accessed: 11 November 2020].

EUA. (2020). Covid-19 and Universities. https://www.eua.eu/issues/27:covid-19-and-universities-ineurope.html

Goodyear, P. (2001). Effective networked learning in higher education: Notes and guidelines. Lancaster: Centre for Studies in Advanced Learning Technology, 3, Networked Learning in Higher Education Project. http://csalt.lancs.ac.uk/jisc/

Graham, C. R., Woodfield, W., \& Harrison, J. B. (2013). A framework for institutional adoption and implementation of blended learning in higher education. The Internet and Higher Education, 18, 4-14. https://doi.org/10.1016/j.iheduc.2012.09.003

Koper, R. (2005). An Introduction to Learning Design. In Learning Design (pp. 3-20). Springer-Verlag. https://doi.org/10.1007/3-540-27360-3_1

OECD. (2020). Education responses to COVID-19: Embracing digital learning and online collaboration.

Radcliffe, D., Wilson, H., Powell, D., \& Tibbetts, B. (2008). Designing next generation places of learning: Collaboration at the pedagogy-space-technology nexus. The University of Queensland, 1-20. http://citeseerx.ist.psu.edu/viewdoc/download?doi=10.1.1.215.788\&rep=rep1\&type=pdf

Sanders, E. B. N., Brandt, E., \& Binder, T. (2010). A framework for organizing the tools and techniques of participatory design. Proceedings of the 11th Biennial Participatory Design Conference on - PDC '10, 195. https://doi.org/10.1145/1900441.1900476

Tovmassian, L. T. (2004). Study on Innovative Learning Environments in School Education.

Trentin, G. (2015). Orientating Pedagogy Towards Hybrid Spaces. Progress in Education, 35(7). https://www.itd.cnr.it/download/2015 - Orientating Pedagogy Towards HS.pdf

UNESCO. (2020). Education in a post-COVID world: Nine ideas for public action International Commission on the Futures of Education. 26.

Author Bios:

Andrea Manciaracina PhD with honours in Design (Politecnico di Milano). Research fellow (Politecnico di Milano) and adjunct professor (Politecnico di Milano) and communication designer. His research focuses on learning spaces, educational technologies, and design tools to support teachers and instructional decision-makers. 